\title{
Editorial: A sympathetic approach to open-angle glaucoma
}

When it comes to trying to untangle the lines of research at present being pursued in the treatment of open-angle glaucoma with sympathomimetic drugs, sympathetic neurone blocking drugs, and alphaand beta-adrenoceptor blocking drugs, the easiest solution would, on the face of it, be to abandon a systematic approach and to resort to empiricism. How else can such seemingly opposed mechanisms of action be reconciled, when each in its turn results in reduction in intraocular pressure? Such an attitude would be understandable, but unhelpful. To form a clearer picture of the reasons why these differing groups of drugs achieve the same object we must resort to a closer examination of the drugs themselves, and to the processes involved in the reduction in intraocular pressure. The mechanisms of action of sympathomimetics present no problem. The lowering of pressure appears to be mediated through either the occupation of alpha-adrenoceptors located in the region of the trabecular meshworks and subserving an increase in the facility of outflow, or the occupation of betaadrenoceptors in the region of the ciliary processes causing a reduction in secretion of aqueous humour. Both processes result in a considerable fall in intraocular pressure. Adrenaline, since it acts at both forms of receptor, suggests itself as the optimum agonist. When, however, we turn to drugs which block sympathetic drive either by a neurone-blocking action, or by alpha- or beta-adrenoceptor blocking activity, the reasoning becomes less straightforward. Certainly, we can explain the ocular hypotensive action of guanethidine, in terms not of its adrenergic neurone-blocking action, but of its known noradrenaline-releasing action, an action which is not sustained, but diminishes tachyphylactically. Similarly, the synergism between adrenaline and guanethidine (in reality potentiation of the effect of adrenaline by guanethidine) can be assigned to a blockade of uptake of adrenaline into adrenergic neurones, thus increasing the effective local concentration of adrenaline at its site of action.
It is when a fall in pressure occurs with receptor blocking drugs that logical explanations fail. A small hypotensive action has been noted with alpha-receptor blocking drugs, but this, when it occurs, is small relative to the fall obtained with agonist drugs. Evidence that beta-adrenoceptor blocking drugs cause a fall is more convincing, although this at times has been ascribed to secondary actions (for example, membrane stabilization) of the drugs rather than to beta-receptor blockade.

In the present issue, further evidence of an effect of beta-receptor blockers is presented, one of which (atenolol) blocks relatively selectively at beta ${ }_{1}$ adrenoceptors. If such an action can be sustained, it could mean that the receptor populations in the eye are more complicated than was first envisaged, and that physiological regulation of intraocular pressure is delicately balanced by a series of differing autonomic influences. A slimmer possibility is that the site of action of the beta-receptor blockers is remote from the orbit, even within the central nervous system (there is a strong possibility that the arterial hypotensive action of betareceptor blocking drugs is central in origin). This would be likely to account only for the action of the systemically administered drug.

Further investigations with the beta-receptor blocking series would appear justified as well as other means of potentiation of, and prolongation of, the action of alpha and beta-receptor agonists. Encouraging results have been obtained by Kitazawa (1975) in the potentiation of the action of adrenaline after 6-hydroxydopamine, although the routine applicability of the technique has yet to be established. Prolongation of the action of sympathomimetic agonists may be effected by the judicious use of a suitable phosphodiesterase inhibitor. It is encouraging also to note the formulation of a suitable combination in one solution of adrenaline and guanethidine.

\section{Reference}

kitazawa, y. (1975) Proceedings of the International Glaucoma Symposium, Albi, (in press) 